\title{
Age as A Predictor of Marital Satisfaction Among Selected Households in Kisii County
}

\author{
Dr Samson Barongo, Phd \\ P.O Box 408-40200- \\ Kisii, Kenya. \\ Lecturer; Kisii University.
}

\begin{abstract}
Marital satisfaction is a significant to the stability of any nation since the family is the basic unit of any nation. Too much marital dissatisfaction may lead to family members being unstable socially which hence societal problems. The purpose of this study therefore sought to establish age in relation to marital satisfaction among selected spouses. The objective for the study: to determine the implication of age at marriage and marital satisfaction. The social exchange theory and attachment theory were adopted to inform the study. The researcher used a correlation design. The population of the study comprised 4,019 spouses and a sample size of 200 spouses was randomly selected for the study. Data was collected by using the Marital Satisfaction Questionnaire. Content and construct validity was ascertained by a pilot study of applying 20 questionnaires outside the area of study by a questionnaire vetted peers. Reliability was established by the calculating Cronbachs' Alfa Coeffecient by administering the questionnaire to 20 respondents who did not take part in the final study. Reliability coefficients of $0.763,0.710,0.716$ and 0.701 were reported and were all above the recommended value. Data analysis was done using statistical techniques of ANOVA, Post Hoc tests and Independent Samples by aid of statistical package of social sciences version 22 . The findings and recommendations were given accordingly at the end of the paper.
\end{abstract}

Keywords: age, predictor, marital, satisfaction households, Kisii County

DOI: $10.7176 /$ RHSS/11-14-05

Publication date:July $31^{\text {st }} 2021$

\section{1: Background of the study}

Marital satisfaction is a special case of relationship satisfaction, and is the degree to which partners in marriages assess their approval of different aspects of their marital relations. Lenthall (2013) in his research on couple attitudes has defined marital satisfaction as a function of the comparison between one's marital expectations and one's marital outcome. He views marital satisfaction as a function of the comparison between one's best available marital alternative and one's marital outcome. Hence, marital satisfaction and marital stability can differ.

Researchers have created inventories assessing everything from sexual satisfaction and function (McCabe and Drake 2000) and overall communication (Hecht, 1978), to interaction affect (Gottman \& Levenson, 2002). Some questionnaires have been created that attempt to measure several variables at once on different (sometimes unfounded and ambiguous) subscales, such as 222 Colgate University Journal of the Sciences intellectual intimacy or attitude to privacy, each assumed, but many times not supported, to relate to overall relationship satisfaction Sternberg (2000). There is a debate as to which overall relationship satisfaction inventory to use, with new ones being created and compared to the last Agelle (2008). The most extensively researched applied approaches that measure variables related to relationship satisfaction are derived from general communication, sexual communication, and interaction affect theories (McCabe and Drake 2000). The communication processes within a couple have been strongly emphasized in relationship counseling, and it has been proposed that "the study of marriage and marital therapy can best be advanced at this time through a better understanding of marital communication processes" (Gottman \& Levenson, 2000). Communication skills have even been claimed to be the "key" and "lifeblood," of a successful relationship (Agelle, 2008). Research has backed up this claim and has found that good communication skills can differentiate satisfied from unsatisfied couples (Meeks, Hendrick, \& Hendrick, 2000; Carstensen, Levenson, \& Gottman, 2000). Other researchers have taken a merely sexual stance, and proposed that sexual communication and the resulting sexual intimacy can alone distinguish satisfied from unsatisfied relationships (Banmen \& Vogel, 2000 ; McCabe, 2000).

In the majority of American families, parents do not communicate with their children about sex, and consequently, young couples have very little adequate preparation for understanding their own sexuality and for later marital dialogue, (Corcoran and Fischer 2000). When the sexual communication breaks down within a couple, this leads to frustration and resentment when neither member of the couple can express their desires. This may further result in people taking on outside sexual partners. Despite the obvious importance of sexual communication skills, there has only been one inventory created to solely measure this communication 
dimension, and despite its use in practice, the research on this is surprisingly quite minimal (McCabe and Drake 2000).

In addition to verbal communication skills, there is a growing body of research that emphasizes the emotions in couple interactions.

Positive and negative affect have been measured in marital interactions, and a higher exchange of negative emotions associated with a low degree of positive emotions is characteristic of both unstable and unsatisfied couples (Carstensen, Gottman, \& Levenson 2000; Gottman , 2000). In addition to simply the level of positive or negative affect, researchers have proposed a balance theory of positive and negative affect in interaction that relates to relationship satisfaction Cartensen et al (2000). The role of affect in interaction is so prominent, that within three minutes of a marital conflict, researchers can now predict divorce using affective measures (Corcoran and Fischer 2000). To date, these approaches have only been extensively tested on married couples. Despite the fact that young exclusive dating relationships provide the foundation for relationships in later life, researchers dismiss these relationships as immature and unstable, although in fact the opposite may be true.

Researchers have blatantly ignored this group with statements like "the usual college dating relationship was, of course, not sufficient for meeting our criteria" (Schaefer and Olson 1981). In this experiment, three models of relationship processes, interpersonal communication, sexual communication, and interaction affect, were compared with an overall measure of relationship adjustment and satisfaction. Using a direct analysis and comparison of these variables, it will be determined which model best relates to overall relationship functioning. This type of multidimensional investigation has never been accomplished in the literature, possibly because researchers approach the subject of relationship satisfaction with predetermined views. This method allows each model a chance to prove its usefulness in predicting relationship satisfaction in a single sample. Researchers have hypothesized that variables that reliably predict relationship satisfaction, however because college relationships are shorter than marriages, basic communication skills is the most salient when assessing relationship satisfaction (Gottman and Levenson, 2000).

In the United states of America and according to a survey conducted by Amato, Booth, Rogers (2007) by the end of the 1990's, the majority of husbands believed that spouses should share breadwinning, that a wife's employment does not interfere with her role as a mother and that husbands should take on a greater share of the housework when their wives are employed. In turn, studies show that the majority of wives expect husbands to perform a greater share of the household chores and child care than in recent decades.

In the U.S.A, traditional gender roles and behaviors have typified men as autonomous, powerful, controlling, assertive, aggressive and self-determined. Within the family, the traditional male role has been one of authority and financial responsibility. U.S. women, on the other hand, have traditionally been considered the caregiver and homemaker. In the mid-1950's, it was a common belief that the husband, acting as head of the household, should have more power than his wife to make key decisions Lucker (2006)

The U.S.A Department of Labor reports that almost $60 \%$ of women were in the workforce in 2004. According to a survey conducted by Amato et al (2007), by the end of the 1990's, the majority of husbands believed that spouses should share breadwinning, that a wife's employment does not interfere with her role as a mother and that husbands should take on a greater share of the housework when their wives are employed. In turn, studies show that the majority of wives expect husbands to perform a greater share of the household chores and child care than in recent decades.

In some developed economies traditional gender roles and behaviors have typified men as autonomous, powerful, controlling, assertive, aggressive and self-determined. Within the family, the traditional male role has been one of authority and financial responsibility. U.S. women, on the other hand, have traditionally been considered the caregiver and homemaker. In the mid-1950's, it was a common belief that the husband, acting as head of the household, should have more say in the family affairs Lucker (2006).

There is empirical evidence that expectations can affect couples in two ways: 1) They can serve as goal structures in which partners can shape and guide their relationship or 2) They can create a "counterfactual" phenomenon, where people compare what has occurred within their relationship to what might have occurred. In essence, the former can cause positive changes within relationships while the latter can create negative outcomes and disappointment. One study by PEW Research Center (2008) in the USA found that "unrealistic expectations" was the major reason that 30 percent of women respondents gave for their divorces in Texas (Together in Texas Baseline Report on Marriage in the Lone Star State, 2008). Thus, it is essential for both members of the couple to understand the gender role expectations of themselves and of their partners throughout the course of the marriage.

In addition results from a 2007 survey conducted by the Pew Research Center showed that respondents reported that "shared household duties" were the third most important component for a successful marriage (out of nine options). Coltrane (2012) and (Shelton, Beth, Daphne 2009) found that women, even when they are employed full time, perform the bulk of routine housework and child care. Amato et al (2007) also found that African-American and Latino husbands both performed more housework than did white husbands. Interestingly, 
the same researchers indicated that men and women between 1980 and 2000 have reported that wives have become happier with their husband's work around the house while husbands have become less happy.

According to a memo entitled "Gender Norms and the Role of the Extended Family" based on expert's discussions at several research meetings on Hispanic healthy marriages, it is important to examine traditional gender roles and family systems in different populations to understand their impact on couple dynamics (memo prepared by ACF, 2005). Although there is research that indicates that traditional Hispanic roles are not as predominant within recent years Amato et al (2007) observes there is contradictory research showing that Hispanic men and women are influenced by traditional and idealized cultural expectations. Such traditional values include a focus on the woman in the marriage as a submissive and dependent mother figure rather than a wife ("marianismo") while the husband is dominant and virile ("machisimo"). There is much discussion between scholars about the positive and negative outcomes that such traditions can create within the family system. The key is to recognize that the degree to which this ideology shapes the Hispanic man and woman prior to their union is going to provide the framework for each individual's expectations of their own gender role within the marriage and for the roles of his or her partner.

Marital satisfaction is a pertinent ingredient to the stability of any nation given that the family is the basic unit of any nation. A study by informal in 2010 showed that only $40 \%$ of Kenyans report being happily married and 3 in 10 said they will marry their current spouse if given a chance to remarry Mcsheffrey (2014). Too much marital dissatisfaction leads to family members being unstable socially which trickles down to societal problems hence to the nation. A higher level of satisfaction is seen as a measure of marital success. It is, therefore, important to study correlates of marital satisfaction in order to determine what variables could potentially predict the outcome of marital success. Spanier (2002) argued that, although the concept of marital satisfaction may seem ambiguous, the growing field of research in this area demands attention. And there is a strong interest in the continued study of how couples form successful marriages, to which the profusion of existing research can attest to some level. In this study, the potential correlates of marital satisfaction are explored in an effort to better understand the marital dyad, especially variables that contribute to its success.

Some research done in the area of marital satisfaction has focused on level of education at time of marriage Heaton (2006). Some of the generalizations of research done agree that there exists virtually unanimous agreement of the association between the age at first marriage and the probability of divorce. And they go further to assert that the younger one is when married, the higher the likelihood of divorce (Snyder, Cozzi, Mangrum, 2005). The researcher has explored that assertion and also queried whether people who marry early are at a higher risk of marital instability than those who marry later in life. One major reason for addressing age is that factors which are negatively related to marital "success" (whether one divorces or remains married) also include many which are related to age at time of marriage, such as low education, , short premarital acquaintance (knowledge and education ). In addition the researcher finds it worth to research and correlate whether personality maladjustment like financial problems, conflicts, social media, absentee spouses, among other variables Burchinal (2005).

(Bumpass, \& Sweet, 2007) studied whether the inverse correlation between level of education at time of marriage and marital instability was attributable to the participant's education, religious affiliation, parental marital stability, or husband's marital history. The study performed a multivariate analysis on a large sample of married, White women under the age of 45, and found that marital instability was not attributable to the aforementioned factors. Their data showed that age at marriage was the strongest single predictor of marital instability in their analysis. This means that, absent of all other seemingly relevant variables, age at time of marriage was the strongest predictor of marital stability. The researcher believes that given the research was done at a global level there needs to correlate age, level of education, gender and courtship and find the strongest predictor of marital satisfaction which might additionally predict marital stability.

(Gorchof and Helson, 2008) studied the relationship between marital satisfaction, age at marriage, and marital role performance. "Role performance" was defined as the extent to which a person acts out what is perceived to be their role socioeconomically and interpersonally in marriage. This study used data from a non random sample of 394 married couples, including spouses' evaluations of role performance in order to gain a more accurate response. All respondents were in their first marriage, had been married six years or less at the time of the study, and were under 35 years of age. Through use of multivariate analysis, Lee found a positive correlation between age at time of marriage and marital satisfaction after studying variables of length of marriage, education, socioeconomic background, and religious importance. This means that as the age at marriage increased, marital satisfaction increased as well. This positive correlation finding was true for both males and females. Lee concluded, however, that the strength of the correlation was moderate at best, and may be related to an unmeasured third variable — potential for remarriage.

(Gorchof and Helson, 2008) also hypothesized and concluded that those who marry young may be cognizant of their better potential to remarry in the event of a divorce, and may then be less willing to tolerate dissatisfaction. Booth (2004) expanded on the research done by Bumpass (2007) and also found out that age at 
marriage was positively correlated with marital satisfaction due to inadequate marriage education in preparation. (Bumpass, 2007, Booth, Edwards, 2004) hypothesized that this situation likely stemmed from inadequate role models or from lack of exposure length to these role models because of early termination of their "marriage apprenticeship" as a result of early marriage. The above researchers felt that people who married at an early age were more likely to experience deficiencies in their marital role performance, which then led to marital dissatisfaction. Data for this study came from a national sample of men and women under 55 years of age who were interviewed by telephone in 1980 .

(Bumpass \& Sweet, 2007) used random digit dialing procedures to locate eligible participants. In total, the analysis involved 1,715 men and women currently in their first marriage. To test their hypothesis they used the MII by Johnson (2008) as well as multiple items to assess role performance, alternatives to the present marriage, and external pressure for marriage. They found that marital instability is the highest for those who married early (before age 20). Those who married in late twenties scored the lowest on marital instability. They found that those who married later than their twenties scored similarly to those that married earlier, which suggested that marital stability may have a curvilinear relationship with age.

(Fiese, Tomcho, Janucho 2010) continued in this similar study of marital satisfaction in relation to age. Their research indicated that both society and the individual benefit when couples form strong marriages, as those unions frequently lead to less involvement in crime and other detrimental activities by spouses and/or offspring. Slowly declining divorce rates over the last eight years may be related to a sharp increase in the average age of brides and grooms during that same span of time Jose (2007). However, overall martial satisfaction had dropped significantly over those past four decades. They further concluded that positive and negative factors that led increased marital satisfaction and marital dissatisfaction, respectively, may not be mutually exclusive (i.e. satisfaction in marriage is a judgment based on criteria that changed both with the age of each partner and that of the marriage).

Jose et al (2007) also examined the effects of age, number of children, employment status, and length of marriage on marital satisfaction. They found that those who married later were more likely to remain married, but also that those who married younger and get divorced are more likely to remarry. Contrary to previously stated results, these researchers found that age had a significant negative effect on the sexual adjustment and marital adjustment of first-married adults. In other words, the older one was at the time of first marriage, the less adjusted the individual would be toward the marriage and, consequently, the less satisfaction one would express. Middle-aged adults seemed to have greater adjustment problems than both young and elderly participants involved in the study.

In Africa, there are also some researches done on marital satisfaction. For instance Owuamanam (2000) did a research in Nigeria among Igbo people in Imo State where 508 participants were selected from 5 local government areas in Imo State using a multi-stage random sampling technique and reported that the most single variable that pointed on marital satisfaction is the aspect of religious inclination and age. Owuamanam (2000) pointed out that the major reason for revelation above is the non tolerance and diverse thinking between Muslims and Christians religious philosophy. Given that on the local scene there are no major contrasts between religious communities, the researcher may not consider religion as a major variable.

Another researcher on marital satisfaction research done in Africa was based in Kenya by Mbugua (2010) the level of marital satisfaction of forty married couples (eighty individuals) at the Africa Inland Church Jericho, Nairobi, Kenya and the study was done through the use the revised Marital Satisfaction Inventory (MSI-R) to measure marital satisfaction in thirteen marriage interactive dimensions, namely: inconsistency, conventionalization, global distress, affective communication, problem-solving communication, aggression, time together, disagreement about finances, sexual dissatisfaction, role orientation, family history of distress, dissatisfaction with children, and conflict over child rearing. A second instrument, the researcher-designed openended questionnaire was also used to assess the premarital counseling practices in Kenya. The scores of the MSI$\mathrm{R}$ and the findings of the researcher-designed open-ended questionnaires were used to assess marital satisfaction in Kenya which in return, would inform current premarital counseling practices in Kenya. The findings were that inconsistency, conventionalization, global distress, affective communication, problem-solving communication, aggression, time together, disagreement about finances, sexual dissatisfaction, role orientation, family history of distress, dissatisfaction with children, and conflict over child rearing were positively affecting marital satisfaction

According to most marital satisfaction scales care for the family, absence of violence and provision of the family basic needs are some of the variables that can predict marital satisfaction. According to Ombati (2013) majority of women selling their goods at the Daraja Mbili market, in Kisii Township Kisii County, end of being mistreated by their husbands and some even demand part of that money from their trade and misuse it and the report gives the figure at $45 \%$. This has, however, brought its share of challenges as men who feel intimidated by their wives resort to violence in the name of conforming to cultural norms. Although, gender based violence, especially in rural areas is decreasing, some men still continue to batter their spouses in a bid to exude their 
power over them. It is against this backdrop that Godia (2013) of the Coalition on Violence Against Women and women, (COVAW) a non-governmental organization has partnered with local leaders and the media the fight against violence to ensure peace at both the family and community level. Godia (2013) notes power imbalance between men and women is one of the causes of family disputes which trickle to the community and threaten peace, unity and development. In Kisii township and in the last one year alone are were many marital issues among them Ochoro (2014) reports of a man who shoot self and wife of infidelity, Obiero (2014) reports of man jailed for 30 years for killing wife. http://whereiskenya.com/domestic-violence-kenya-tradition-stay quotes UNIFEM Kenya that $80 \%$ of Kisii and Borana men abuse their wives. (Ochoro 2014, Obiero 2014) reported cases of marital dissatisfaction among the spouses in Kisii Township. It is against this background that the present study investigated how selected biographical variables relate to marital satisfaction among spouses in Kisii Township.

\section{2: Statement of the problem}

Ideally marriages should be productive in terms of optimal levels of satisfaction. However, cases of marital dissatisfaction have been reported among spouses in Kisii County (Makori 2014, Ochoro 2014, Obiero 2014). It is also believed that expectations of marriage have changed over time, with socioeconomic and societal perceptions on age, and how it influences influence marital satisfaction. Marital satisfaction should be a construct for preservation of a marriage as well as increased personal well-being. The researcher therefore seeks to explore differences in marital satisfaction on the basis of age, level of education, marital experience and gender the dynamics therein and how they affect marital satisfaction. The researcher queries that assumptions made and conclusions reached are not enough given that no research has been done in Kisii Township of Kisii County in particular and hence research needs to be done to generalize them to Kisii Township of Kisii County.

\section{3: Objective:}

To find out the differences in marital satisfaction on the basis of age at marriage among spouses in Kisii Township in Kisii County.

\section{4: Hypothesis}

There is no statistical differences between age and marital satisfaction among selected households in Kisii County, Kenya.

\section{5: LITERATURE REVIEW}

(Imhonde, Oyaziwo, Aluede, Ifunanyachuku, 2008) examined age and marital satisfaction among other variables as determinants of marital satisfaction among newly wedded couples in a Nigerian University. A total of 150 (80 males and 70 females) selected from married students and staff of Ambrose Alli University, Ekpoma participated in the study. The study used a questionnaire comprising the demographic variables, dyadic adjustment scale and communication scale was used to test the hypotheses that there is a relationship between age and marital satisfaction. Though there was an interaction effect of age and communication on marital satisfaction.

(Story, Berg, Smith, Henry, Beveridge, Pearce 2007) examined age and the spouses' positive attitude towards their spouses and whether that positive attitude overrides the spouse's actual behavior. Participants included 270 middle-aged (40-50 years old) and older (60-70 years old) couples who discussed a marital disagreement and completed an errand task. Couples provided appraisals of their spouse's affiliation, and the authors coded affiliative interactions using the structural analysis of social behavior. Hierarchical multivariate linear modeling indicated that older husbands and wives viewed their spouse's behavior as more positive during disagreement interactions than did independent observers; in the errand task, only older wives demonstrated positive sentiment override.

Elizabeth (2009) studied the relationship between age and marital satisfaction on a secondary analysis of 77 couples dealing with breast cancer and examined the relationship between age and marital satisfaction. The couples' marital satisfaction was measured using the Satisfaction and Cohesion Subscales of the Revised Dyadic Adjustment Scale. In analyzing age and marital satisfaction, husbands and wives were evaluated individually, using their age at the time of their entrance into the study. A correlation analysis was used to determine any significance between age and marital satisfaction. Then a multiple regression with age stratified into high and low was used with an interaction term of age perceived criticism to find out if perceived criticism was a moderating variable. Findings from this study did not support the hypothesis that there was a significant correlation between age and marital satisfaction alone, and that older individuals would experience higher marital satisfaction.

(Lantinga , Krauss, Carey, Spector 2006) upon research and review of some data found out that the variables of age at time of marriage were not significantly correlated with marital satisfaction among college 
graduates. Dyadic differences in age were also not significantly correlated with either marital satisfaction or marital adjustment. In the study participants were $(\mathrm{N}=60)$ who responded to this survey were predominantly Caucasian $(85 \%, n=52), 5 \%(n=3)$ were Hispanic, and $10 \%(n=6)$ were bi-or multi-racial. This varies from the national average, which is $79.8 \%$ Caucasian, $15.4 \%$ Hispanic, and $1.7 \%$ bi-or multi-racial (U.S. Census Bureau, 2010). All respondents had high school diplomas. Additionally, 53.3\% $(\mathrm{n}=32)$ of respondents had completed a bachelor's degree or higher at the time of the survey. This level of education is higher than the national average of $80.4 \%$ of high school graduates and higher than the national average of $24.4 \%$ college graduates.

(Bradbury, Fincham, Bench 2006) found a strong correlation between the two variables of age and marital satisfaction where the results from this sample did not show a statistically significant relationship between these variables. This may be related to this particular sample, as the majority of respondents $(n=50)$ were married in their twenties (between the ages of 20 and 28). There may not be a diverse enough sample to measure the relationship between age and marital satisfaction. Even when the survey results are further parsed into dyadic satisfaction and overall dyadic adjustment scores, age was still not significantly correlated with these measures. In this sample, it was found that there was no relationship between age at time of marriage and marital satisfaction.

Bradbury (2009) reviewed a small sample of 50 participants and the findings can not be generalized to other bigger populations. Hence the current research has filled gaps in literature by using a larger sample size of 200 against the previous one of 50. Additionally, the previous research used spouses married between ages 20 and 28 where as the present also fills gaps in literature by using spouses of all ages.

Nivischi (2009) investigated age as one of the factors that affect marital satisfaction among black Jamaicans and African Americans living in the United States. The purpose of this previous study of was to investigate among other factors age and marital satisfaction. The factors investigated included the effects of age, education, gender, educational attainment, social support, and religion on the marital satisfaction of these two groups. The research hypothesis was that there was no relative significance between age and marital satisfaction. A Multinomial Logistic Regression analysis performed among the variables. Findings indicated that age, gender, and educational attainment level were significant predictors of marital satisfaction.

(Bumpass, Sweet , 2007) studied whether the inverse correlation between age at time of marriage and marital instability and satisfaction and found individuals who marry early in life are more unstable in marriage than those who marry later in life. Bumpass et al (2007) research was performed on a multivariate analysis on a large sample of married, White women under the age of 45 , and found that marital instability was not attributable to marrying early in age. Their data showed that younger age at marriage was the strongest single predictor of marital instability in their analysis. This means that, absent of all other seemingly relevant variables, age at time of marriage was the strongest predictor of marital stability.

Lee (2007) studied the relationship between marital satisfaction, age at marriage, and marital role performance. Lee (2007) study used data from a nonrandom sample of 394 married couples, including spouses' evaluations of role performance in order to gain a more accurate response. All respondents were in their first marriage, had been married six years or less at the time of the study, and were under 35 years of age. Through use of multivariate analysis, the study found a positive correlation between age at time of marriage and marital satisfaction after controlling for the antecedent variables of length of marriage, education, socioeconomic background, and religious importance. This means that as the age at marriage increased, marital satisfaction increased as well. This positive correlation finding was true for both males and females.

Bumpass et al (2007) study found that age at marriage was positively correlated with marital satisfaction due to inadequate preparation. He hypothesized that this situation likely stemmed from inadequate role models or from lack of exposure length to these role models because of early termination of their "marriage apprenticeship as a result of early marriage. Data for this study came from a national sample of men and women under 55 years of age who were interviewed by telephone. Researchers used random digit dialing procedures to locate eligible participants. In total, the analysis involved 1,715 men and women currently in their first marriage. To test their hypotheses that early marriage was related to marital instability and poor role performance, and to control for the confounding variable of external pressure for marriage. They found that marital instability is the highest for those who married early (before age 20). Those who married in their twenties scored the lowest on marital instability. They found that those who married later than their twenties scored similarly to those that married earlier, which suggested that marital stability may have a curvilinear relationship with age.

Bumpass et al (2007) research reported findings on spouses who were below 55 years and were interviewed on phone. Therefore, the present research has filled gaps on literature by including spouses beyond 55 years and literature on those spouses interviewed directly by a questionnaire.

Bradbury et al (2006) continued in this similar study of marital satisfaction in relation to age. Their research of 500 spouses indicated that both society and the individual benefit when couples form strong marriages, as those unions frequently lead to less involvement in crime and other detrimental activities by spouses and/or offspring. This previous research used spouses who were married for less than 6 years. The research 
generalized that gradual declining divorce rates over the last eight years may be related to a sharp increase in the average age of brides and grooms during that same span of time; however, overall martial satisfaction has dropped significantly over the past four decades, and continues to noticeably decline for nearly all couples during the first decade of marriage. Furthermore, the positive and negative factors that led to both increased marital satisfaction and marital dissatisfaction, respectively, may not be mutually exclusive (i.e. satisfaction in marriage is a judgment based on criteria that changed both with the age of each partner and that of the marriage).

Jose et al (2007) examined the effects of age, number of children, employment status, and length of marriage on marital satisfaction. Jose et al (2007) research had a sample of $(\mathrm{N}=60)$ and found that those who married later were more likely to remain married, but also that those who married younger and get divorced are more likely to remarry. Jose et al (2007) also found out that there was no statistical significance between age and marital satisfaction. In other words, the older one was at the time of first marriage, the less adjusted the individual would be toward the marriage and, consequently, the less satisfaction one would express. Middle-aged adults seemed to have greater adjustment problems than both young and elderly participants involved in the study. These researchers also found an effect related to education level.

Cohen (2010) argued that marriage was good for men and bad for women. Subsequent research noted that wives, on average, reported lower marital satisfaction than husbands. Furthermore, when differences within couples existed on marital satisfaction, the wife was usually the less satisfied spouse; however, most previous studies of the gender/marital satisfaction relationship had not been based on nationally representative samples. A nationally representative sample from the 1988 Survey of Families and Households in the USA was used to assess the relationship of gender with marital satisfaction. Within-couple analyses indicated that wives were less satisfied with their marriages than husbands and that, when substantial within-couple differences occurred with respect to marital satisfaction, the wife was usually the less satisfied spouse. Results provide at least small support for feminist assertions about the relatively adverse nature of marriage for women in the United States.

Alder (2010) examined age and marital satisfaction where the purpose of her study was to determine whether there is a relationship between marital satisfaction (as measured by the Dyadic Adjustment Scale; Spanier, 1976) and the independent variables of age, education level, and courtship length (parsed into pre- and post-engagement periods). Respondents $(N=60)$ were required to complete surveys online regarding their experiences in their marriages. This research was approved by the institutional review board of Pacific University in February 2009. Results indicated that there was not a statistically significant relationship between marital satisfaction, age, education level, and courtship length.

Alser (2010) research was done outside Kenya and more so the study participants were relatively few as compared to the current study. Thus the current study has filled gaps in literature in the Kenyan context and also including more participants.

Adejumo (2011) studied the determinants of life satisfaction among the elderly in Nigeria. A survey research design was adopted for this study where a total of 194 participants were randomly selected. These participants from these previous were made up of 77 males and 117 females. Their ages ranged from 60-88 years with standard deviation 65.4years. Four research hypotheses were raised and tested. However, no significant differences were found in life satisfaction and marriage on the bases of gender, age, and marital. It was concluded that the reason for the low level of life satisfaction among the elders was due to the weak nature of the care and social support available to the elderly due to changes in the family system in Nigeria.

Gilad et al (2009) reviewed study was a longitudinal study which took a considerable amount of time and in total it took a period of 15 years, which could have led to drop out of participants in the course of study. However, the current research was carried out in a shorter span of time. Therefore, the current research has filled gaps in literature by a similar research like the previous research but on a cross sectional study research.

Owuamanam (2000) study investigated the contributions of age at marriage and religion couples to marital satisfaction among Igbo people in Imo State, Nigeria. 580 subjects were selected from 5 local government areas in Imo State using a multi-stage random sampling technique. A questionnaire titled "Marital Satisfaction Questionnaire" constructed and validated by the researcher was used to collect data for the study. Results of the study showed that age at marriage and the couple's religion were significantly related to marital satisfaction.

Owuamanam (2000) study was done among religious groups of individuals only and more so it was done in Nigeria and not in Kenya. Therefore, the current research has filled gaps in literature by providing the findings on the Kenyan context.

\section{6: METHODOLOGY}

According to Creswell (2012) a research design is a systematic plan to study a scientific problem. The design of a study defines the study type where for the case of this research it was correlation survey design. Creswell (2012) asserts that correlation survey design is used where the researcher wanted to collect much information from many subjects at one time, he could also study a wide range of variables and their interrelations. The researcher could also study variables that were not easily produced in the laboratory. However, that correlation 
could not indicate causation. The design involved the measurements of the study, variables so as to determine and estimate the extent to which the values for the variables are related. The design entailed uses of correlation coefficients which are statistics used to measure the strength between variables.

The target population comprised of all the married spouses in Kisii Township in Kisii County. There are approximately 4019 spouses according to 2009 census in Kisii Township of Kisii County. This study population was chosen because the information required could be obtained from them.

Sample size refers to the act, process, or technique of selecting an appropriate sample. The sample size was an important feature of this empirical study in which the goal was to make inferences about a population from the sample. In practice, the sample size used in a study was determined based on the expense of data collection, and the need to have sufficient statistical power Gay (2006).

There are approximately 4,019 spouses (source 2009 census). According to Gay (2006), as shown in the table below, a sample of $5 \%$ of the total population is a good representative of the target population for populations that are between 4001 to 10,000 so as to ensure homogeneity, size and accuracy. Therefore the study utilized 200 respondents as per the principle above which were chosen by simple random sampling.

Table 1.1: Population sampling Table

\begin{tabular}{llllll}
\hline Size of population & 0 to & 101 to & 1001 to & 5001 to & $10,000+$ \\
& 100 & 1000 & -5000 & 10000 & \\
\hline Percentage of population & $100 \%$ & $10 \%$ & $5 \%$ & $3 \%$ & $1 \%$ \\
\hline
\end{tabular}

Source: (Gay, 2006)

1.6.1: Sampling technique

According to (Mugenda \& Mugenda (2003) simple random sampling is used when a large number of individuals, subjects or phenomena exist in the sample size you are targeting to study. As such simple random sampling (SRS) was used so as to eliminate the systematic bias. Subsequently all the individuals were given an equal chance to participate in the study.

\subsection{2: Validity of Questionnaire}

Validity of questionnaire refers to how well a scientific test or piece of research actually measures what it sets out to, or how well it reflects the reality it claims to represent (Creswell , 2012). Like reliability, validity in this sense is a concept drawn from the positivist scientific tradition and needs specific interpretation and usage in the context of qualitative research. Content validity was maintained by re- examining the questions to ensured they capture the needed data (Creswell , 2012). The research peers, research experts evaluated all aspects such that the instruments focused on the required information. Construct validity ensured that the instruments obtained the anticipated view, attitudes and perceptions on the subject under research. Validity of questionnaire was ensured by expert judgement of university lecturers of Jaramogi Oginga Odinga University of Science \& Technology. Finally, the items in the questionnaire were arranged from the simple to the most complex.

\subsection{2: Reliability of Questionnaire}

Reliability is yielding the same or compatible results in different clinical experiments or statistical trials (Creswell, 2012). To ensure reliability of instruments, a pilot study was conducted with respondents who had similar thematic characteristics to the ones the study and were residing in the area of the study but were not included in the main study. Therefore, a sample size of 20 respondents were given the research questions which they filled. A test retest coefficient reliability values was the calculated using Cronbach alpha coefficients Cronbach (2004). The results were presented in the table 3.2 .

Table 1.2: Cronbach Alfa co efficient output

\begin{tabular}{lcc}
\hline Variable & No of items & Cronbach Alfa \\
\hline Age & 8 & 0.763 \\
Education & 5 & 0.710 \\
Experience & 7 & 0.716 \\
Marital satisfaction & 15 & 0.701 \\
\hline
\end{tabular}

The questionnaire items used to measure the variables were reliable as they indicated by the Cronbach values were above 0.70 for all the variables. This value is above the recommended as proposed by Kothari (2006) that reliable questionnaire should have a reliability coefficient of $\mathrm{r}=0.6$ and above.

\subsection{3: Data Analysis}

The responses from the questionnaires were thoroughly edited for completeness accuracy, uniformity, consistency and comprehensibility. his was then followed by coding which involved translating answers given by the respondents into measuring the categories and giving them numerical codes so as to make them easy for entering into the computer for analysis. For analysis, the data was entered into the computer using the statistical packages for social sciences (SPSS) version 21. Frequency percentages were then used to analyze beyond characteristics of the respondents. Then statistical chi squares were then derived and interpretation was done and results discussed. Specifically, the statistical tests such as pearson correlations, t-test, Analysis of Variance and 
Post Hoc comparisons were used to test the hypotheses. The hypotheses were tested at $5 \%$ level of significance. When the obtained value was less than .05 , the null hypothesis was rejected but when the obtained value was greater than .05 , the null hypothesis was accepted.

\section{7: RESULTS}

Findings on differences in marital satisfaction on the basis of age at marriage

Null Hypothesis 1

There are no statistically significant differences in marital satisfaction on the basis of age at marriage among elected spouses in Kisii Township, Kisii County Kenya

The aim of this hypothesis was to determine whether the age at marriage has an influence in marital satisfaction. The study evaluated marital satisfaction in relation to age and the results are as presented below. There were 6 age categories of the spouses. The one way ANOVA was used to analyze the data. The results are presented in the Table 4.1.

Table 1.3: Descriptive statistics on differences in age at marriage and marital satisfaction

N Mean $\quad$ Std. $\quad$ Std. $\quad 95 \%$ Confidence Interval for Minimum Maximum

Deviation Error

\begin{tabular}{|c|c|c|c|c|c|c|c|c|}
\hline Less than 20 & 15 & 4.53 & .516 & .133 & 4.25 & 4.82 & 4 & 5 \\
\hline Years & & & & & & & & \\
\hline $21-25$ Years & 19 & 3.42 & .507 & .116 & 3.18 & 3.67 & 3 & 4 \\
\hline $26-30$ Years & 50 & 3.80 & .948 & .134 & 3.53 & 4.07 & 2 & 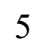 \\
\hline $31-35$ Years & 60 & 3.18 & 1.652 & .213 & 2.76 & 3.61 & 1 & 5 \\
\hline $36-40$ Years & 40 & 2.88 & 1.042 & .165 & 2.54 & 3.21 & 2 & \\
\hline $41-45$ Years & 15 & 3.33 & 1.877 & .485 & 2.29 & 4.37 & 1 & כ \\
\hline Total & 199 & 3.41 & 1.322 & .094 & 3.23 & 3.60 & 1 & \\
\hline
\end{tabular}

From the descriptive statistics in Table 1.3, the spouses who were married at a young tender age (less than 20) were the most satisfied with a mean of 4.53, followed by those who married at 26-30 with a mean of 3.80, then followed by those who married at 21-25 with a mean of 3.42, the those who married at 41-45 with a mean of 3.33, the age group 31- 35 with a mean of 3.18 and least satisfied age group 36-40 with a mean 2.88.

One way ANOVA was used to test the significance differences on marital satisfaction on the basis of age. The results are presented on Table 4.2

Table 1.4 : ANOVA on differences in age at marriage and marital satisfaction maritalsatscale

\begin{tabular}{lrrrrr} 
& Sum of Squares & Df & Mean Square & F & Sig. \\
\hline Between Groups & 41.154 & 5 & 8.231 & 5.207 & .000 \\
Within Groups & 305.057 & 193 & 1.581 & & \\
\hline Total & $\mathbf{3 4 6 . 2 1 1}$ & $\mathbf{1 9 8}$ & & & \\
\hline
\end{tabular}

From the statistical analysis in the Table 1.4 , the calculated $\mathrm{p}$ value indicating the significance of age at marriage was .000 . Subsequently $(\mathrm{P}<.05)$ in all different age groups at marriage. Therefore, the null hypothesis stating that there is no statistically significant relationship between age at marriage and marital satisfaction was rejected. This implies that, marital satisfaction has relationship with age at marriage. Consequently, the researcher accepted the alternative hypothesis that there is a statistical significant difference in marital satisfaction on the basis of age at marriage and marital satisfaction. To examine where the differences in marital satisfaction lies among the age groups, a Post Hoc was carried out and the results are presented in Table 4.3. 
Table 1.5: Post Hoc Tests for differences in marital satisfaction on the basis of age at marriage

Dependent Variable: maritalsatscale Tukey HSD

\begin{tabular}{|c|c|c|c|c|c|c|}
\hline $\begin{array}{l}\text { (I) Age Bracket at } \\
\text { Marriage }\end{array}$ & $\begin{array}{l}\text { (J) Age Bracket at } \\
\text { Marriage }\end{array}$ & $\begin{array}{c}\text { Mean Difference } \\
(\mathrm{I}-\mathrm{J})\end{array}$ & $\begin{array}{l}\text { Std. } \\
\text { Error }\end{array}$ & Sig. & $\begin{array}{c}95 \% \text { Confide } \\
\text { Lower } \\
\text { Bound }\end{array}$ & $\begin{array}{l}\text { Interval } \\
\text { Upper } \\
\text { Bound }\end{array}$ \\
\hline \multirow{5}{*}{ Less than 20 Years } & $21-25$ Years & 1.112 & .434 & .112 & -.14 & 2.36 \\
\hline & $26-30$ Years & .733 & .370 & .357 & -.33 & 1.80 \\
\hline & $31-35$ Years & $1.350^{*}$ & .363 & .004 & .31 & 2.39 \\
\hline & $36-40$ Years & $1.658^{*}$ & .381 & .000 & .56 & 2.75 \\
\hline & $41-45$ Years & 1.200 & .459 & .099 & -.12 & 2.52 \\
\hline \multirow{5}{*}{$21-25$ Years } & Less than 20 Years & -1.112 & .434 & .112 & -2.36 & .14 \\
\hline & $26-30$ Years & -.379 & .339 & .873 & -1.35 & .60 \\
\hline & $31-35$ Years & .238 & .331 & .980 & -.71 & 1.19 \\
\hline & $36-40$ Years & .546 & .350 & .627 & -.46 & 1.55 \\
\hline & $41-45$ Years & .088 & .434 & 1.000 & -1.16 & 1.34 \\
\hline \multirow{5}{*}{$26-30$ Years } & Less than 20 Years & -.733 & .370 & .357 & -1.80 & .33 \\
\hline & $21-25$ Years & .379 & .339 & .873 & -.60 & 1.35 \\
\hline & $31-35$ Years & .617 & .241 & .112 & -.08 & 1.31 \\
\hline & $36-40$ Years & $.925^{*}$ & .267 & .008 & .16 & 1.69 \\
\hline & $41-45$ Years & .467 & .370 & .806 & -.60 & 1.53 \\
\hline \multirow{5}{*}{$31-35$ Years } & Less than 20 Years & $-1.350^{*}$ & .363 & .004 & -2.39 & -.31 \\
\hline & $21-25$ Years & -.238 & .331 & .980 & -1.19 & .71 \\
\hline & $26-30$ Years & -.617 & .241 & .112 & -1.31 & .08 \\
\hline & $36-40$ Years & .308 & .257 & .836 & -.43 & 1.05 \\
\hline & $41-45$ Years & -.150 & .363 & .998 & -1.19 & .89 \\
\hline \multirow{5}{*}{$36-40$ Years } & Less than 20 Years & $-1.658^{*}$ & .381 & .000 & -2.75 & -.56 \\
\hline & $21-25$ Years & -.546 & .350 & .627 & -1.55 & .46 \\
\hline & $26-30$ Years & $-.925^{*}$ & .267 & .008 & -1.69 & -.16 \\
\hline & $31-35$ Years & -.308 & .257 & .836 & -1.05 & .43 \\
\hline & $41-45$ Years & -.458 & .381 & .834 & -1.55 & .64 \\
\hline \multirow{5}{*}{$41-45$ Years } & Less than 20 Years & -1.200 & .459 & .099 & -2.52 & .12 \\
\hline & $21-25$ Years & -.088 & .434 & 1.000 & -1.34 & 1.16 \\
\hline & $26-30$ Years & -.467 & .370 & .806 & -1.53 & .60 \\
\hline & 31 - 35 Years & .150 & .363 & .998 & -.89 & 1.19 \\
\hline & $36-40$ Years & .458 & .381 & .834 & -.64 & 1.55 \\
\hline
\end{tabular}

*. The mean difference is significant at the 0.05 level.

The Tukeys Post Hoc comparison results presented in Table 1.5 indicates that there were statistically significant differences in marital satisfaction on the basis of age between spouses in the age groups less than 20 years and those in $31-35$ years, $(p$ value $=0.004)$; and 36 years ( $p$ value $=0.000$ ); between spouses in $26-30$ years and those in less than 20 years $(\mathrm{p}$ value $=0.004)$ and finally between those in $31-35$ years and those in less than 20 years $(\mathrm{p}$ value $=0.000)$. Generally, there are significant statistical differences between age at marriage and marriage satisfaction but not critical according to the findings above.

These findings are similar to Imhonde et al (2008) who found out that there was an interaction effect of age and communication on marital satisfaction. In addition, Story et al (2007) examined age and the spouses' positive attitude towards their spouses and whether that positive attitude overrides the spouse's actual behavior depending on age and found similar results with the current ones that age and marital satisfaction are related. Nivischi (2009) investigated age as one of the major factors that affect marital satisfaction among spouses. Similar generalization was found by Bumpass et al (2007) who studied whether the inverse correlation between age at time of marriage and marital instability and satisfaction and found individuals who marry early in life are more unstable in marriage than those who marry later in life. Lee (2007) studied the relationship between marital satisfaction, age at marriage, and marital role performance. This means that as the age at marriage increased, marital satisfaction increased as well. This positive correlation finding was true for both males and females. Bradbury et al (2006) continued in this similar study of marital satisfaction in relation to age. The research generalized that gradual declining divorce rates over the last eight years may be related to a sharp increase in the average age of brides and grooms during that same span of time. Bumpass et al (2007) study found that age at marriage was positively correlated with marital satisfaction due to inadequate preparation. Gilad (2009) study 
also revealed that marital satisfaction declined over 15 years for both husbands and wives and hence the notion that marital satisfaction was had a relationship with age of spouses husbands. Owuamanam (2000) study reiterates that age at marriage and the couple's religion were significantly related to marital satisfaction.

Some researchers were contrary to the current study where for instance, Elizabeth (2009) studied the relationship between age and marital satisfaction and findings of the study did not support the hypothesis that there was a significant correlation between age and marital satisfaction alone, and that older individuals would experience higher marital satisfaction. Lantinga (2006) upon research and review of some data also was contrary and found out that the variables of age at time of marriage were not significantly correlated with marital satisfaction among college graduates. Bradbury et al (2006) did not generalize as the current study when he found a strong correlation between the two variables of age and marital satisfaction where the results from this sample did not show a statistically significant relationship between these variables. Jose et al (2007) found out that there was no statistical significance between age and marital satisfaction. Alder (2010) study concluded that there was not a statistically significant relationship between marital satisfaction and age. Adejumo (2011) when studying the determinants of life satisfaction among the elderly also found contrary results that no significant differences were found in life satisfaction and marriage on the bases of age $\mathrm{P}>.05$.

\section{REFERENCES}

Adejumo, G. O \& Oyedepo, T. (2011). Age, Marital Status, Gender and Job Status as Determinants of Life Satisfaction among the Elderly in Nigeria Issues and Researches on Adults and Aged in Nigeria. Covenant university. https://www.google.com/?gws_rd=ssl\#q=adejumo+on+age+and+marital+satisfaction.

Agelle, H. (2008). Predictors of relationship satisfaction; the link between Cognitive flexibility, compassion love, and the level of differentiation. Retrieved from https://books.google.co.ke/books? On $10^{\text {th }}$ January 2015.

Alder, E. S. (2010). Age, Education Level, and Length of Courtship in Relation to Marital Satisfaction. (Master's thesis, Pacific University). Retrieved from: http://commons.pacificu.edu/spp/145 on 15th January 2015

Amato, P. R., Booth, A., \& Rogers, S.J. (2007). Alone Together How Marriage in America is Changing. Cambridge, MA: Harvard University Press (p. 148).

Bradbury, T. N., Fincham, F. D., \& Beach, S. R. H. (2000). Research on the nature and determinants of marital satisfaction: A decade in review. Journal of Marriage and the Family, 62, 954-980.

Bradbury, T. Fincham, F. \& Beach, S. (2006). Research on the nature and determinants of marital satisfaction: A decade in review. Journal of Marriage and the Family, 62, 954-980

Bumpass, L. L. \& Sweet, J. A. (2007). Differentials in marital instability. American Sociological Review, 37(12), 754-766.

Bumpass, Choe \& Rindfuss Tsuya (2005). Relationships between marriage and womens health. Journal of Health. Doi paa2008.princeton.edu/papers/81362 on 10 th JUNE 2014.

Coltrane, S. (2012). Family Man: Fatherhood, Housework and Gender Equity. New York: Oxford University Press.

Creswell, J.W. (2012). Educational research: Planning, conducting, and evaluating quantitative and qualitative research. Upper Saddle River, NJ: Prentice Hall.

Corcoran, K., \& Fischer, J. (2000). Measures for clinical practice: A sourcebook (Vol. 1). New York, NY: The Free Press.

Daphne Stevens, Gary Kiger \& Pamela J. Riley. (2004). Working Hard and Hardly Working. Volume.wiley.com vol 63, Issue 2, pages 514-526, http;//onlinelibrary

Elder, G. H. (1969). Appearance and education in marriage mobility. American Sociological Review, 34(4), 519-533.

Elizabeth D. (2009). Age and marital satisfaction in couples with cancer. Purdue University - Main Campus. http://docs.lib.purdue.edu/cfstheses/6/

Gay L.R (2006). Educational Research: Competencies for Analysis and Application, $3^{\text {rd }}$ edition. Columbus, Ohio: Merrill Publishing Company, 101

Gorchoff S M, Helson R (2008). Contextualizing change in marital satisfaction during middle- age: An 18-year longitudinal study. Psychological Science.19:1194-1200

Heaton, T. B. (2006). Factors contributing to increasing marital stability in the United States. Journal of Family Issues, 23(3), 392-409. doi: 10.1177/0192513X02023003004

Imhonde Henry O, Oyaziwo Aluede and N.R. Ifunanyachukwu (2008). Effective Communication, Educational Qualification and Age as Determinants of Marital Satisfaction among Newly Wedded-Couples in a Nigerian University. Pakistan Journal of Social Sciences; Volume: 5 | Issue: 5 | Page No.: 433-437

Jose, O. \& Alfons, V. (2007). Do demographics affect marital satisfaction? Journal of Sex \& Marital Therapy, 33 , 73 - 85. Doi: 10.1080/00926230600998573

Lantinga, L. J., \& Krauss, D. J Carey, M. P., Spector, I. P. (2006). Reliability of marital Dyadic Adjustment 
Scale. Psychological Assessment, 5(2), 238-240.doi: 1040 -3 590/93 parenthood. Journal of Family Psychology; 21:155-164.

Lee, G. R. (2007). Age at marriage and marital satisfaction: A multivariate analysis with implications for marital stability. Journal of Marriage and the Family, 39(3), 493-504

Lenthall Gerald (2013). Marital Satisfaction among Spouses. Journal of Marriage and Family Counseling Vol 3 iss 4.pages 65-74. Retrieved from http://eric.ed.gov/?id=EJ169345.

Luker Kristin (2006). When Sex Goes to School: Warring Views on Sex and Sex Education Since the Sixties (New York: W.W. Norton \& Company, 75

Mahdieh Yazdanpanah, Mohammad Eslami, and Nouzar Nakhaee (2014).Effectiveness of the Premarital Education Programme in Iran. International Scholarly Research Notices; Volume 2014, Article ID 964087, http://dx.doi.org/10.1155/2014/964087.

Makori A . (2014). Kisii County registers high cases of gender based violence. http://www.hivisasa.com, kisii/news/124692/kisii-county-registers-high-cases-gender-based-violence

Mcshefferey Eliszabeth (2014). Married for 80 years and still in love. Saturday nation, 30th August 2014, Pg 3.

Nivischi Ngozi, Edwards (2009). Marital satisfaction: Factors for black Jamaicans and African Americans living in the United States. Pro Quest Dissertations \& Theses : gradworks.umi.com/33/83/3383655.html

Obiero I. (2014, October ,29). A man jailed for 30 years for killing wife. Hivi sasa online newspaper. Retreved from http://www.hivisasa.com/kisii/crime/115393/

Ochoro R. (2014, June 9th ). Ap shoots wife, self in Kisii Town. Weekly Star. Pg 20

Ombati R (2013). Violence used to oppress women in Kisii. The Kenya Woman Magazine. Advocating for the rights of women: Issue No 39

Owuamanam T O. (2000). Age at Marriage, Religion and Marital Satisfaction among Igbo People in Imo State. The Nigerian Journal of Guidance and Counseling Vol. 7 (1): pp.110-120.

PEW Research Center (2008). "Women Call the Shots at Home: Public Mixed on Gender Roles in jobs."'Retrieved June 12, 2009 from http://pewresearch.org/pubs/967/gender-power

Spanier, G. B. (2002). Measuring dyadic adjustment: New scales for assessing the quality of marriage and similar dyads. Journal of Marriage and the Family, 38, 15-28.33

Shapiro AF Gottman JK, Carrere S (2000). The baby and the marriage: Identifying factors that buffer against decline in marital satisfaction after the first baby arrives. Journal of Family Psychology 14:59-70

Sternberg R.J (2000). Successful Inteligence Newyork : Plume publishers

Story TN, Berg CA, Smith TW, Beveridge R, Henry NJ, Pearce G. (2007). Age, marital satisfaction, and optimism as predictors of positive sentiment override in middle-aged and older married couples. Pubmed.org. Dec; 22(4):719-27. doi: 10.1037/0882-7974.22.4.719.

Snyder, D. K., Cozzi, J. J., \& Mangrum, L. F. (2005). Conceptual issues in assessing couples and families. (Eds.), Family psychology: Science-based interventions (pp. 69- 87). Washington, DC:

Tucker, M. W. \& O’Grady, K. E. (2004). Effects of physical attractiveness, intelligence, age at marriage, and cohabitation on the perception of marital satisfaction. The Journal of Social Psychology, 131(2), 253-269. 